\title{
A System Dynamics Approach to Modeling Future Climate Scenarios: Quantifying and Projecting Patterns of Evapotranspiration and Precipitation in the Salton Sea Watershed
}

\author{
Michael E. Kjelland, ${ }^{1,2}$ Todd M. Swannack, ${ }^{1}$ and William E. Grant ${ }^{2}$ \\ ${ }^{1}$ U.S. Army Engineer Research and Development Center, Environmental Laboratory, Vicksburg, MS 39180-6199, USA \\ ${ }^{2}$ Department of Wildife \& Fisheries Sciences, Texas A\&M University, College Station, TX 77843, USA \\ Correspondence should be addressed to Michael E. Kjelland; michael.e.kjelland@usace.army.mil
}

Received 14 February 2014; Revised 17 April 2014; Accepted 18 April 2014; Published 19 May 2014

Academic Editor: Dong Jiang

Copyright (C) 2014 Michael E. Kjelland et al. This is an open access article distributed under the Creative Commons Attribution License, which permits unrestricted use, distribution, and reproduction in any medium, provided the original work is properly cited.

\begin{abstract}
The need for improved quantitative precipitation forecasts and realistic assessments of the regional impacts of natural climate variability and climate change has generated increased interest in regional (i.e., systems-scale) climate simulation. The Salton Sea Stochastic Simulation Model $\left(S^{4} \mathrm{M}\right)$ was developed to assist planners and residents of the Salton Sea (SS) transboundary watershed (USA and Mexico) in making sound policy decisions regarding complex water-related issues. In order to develop the $\mathrm{S}^{4} \mathrm{M}$ with a higher degree of climate forecasting resolution, an in-depth analysis was conducted regarding precipitation and evapotranspiration for the semiarid region of the watershed. Weather station data were compiled for both precipitation and evapotranspiration from 1980 to 2004. Several logistic regression models were developed for determining the relationships among precipitation events, that is, duration and volume, and evapotranspiration levels. These data were then used to develop a stochastic weather generator for $S^{4} \mathrm{M}$. Analyses revealed that the cumulative effects and changes of \pm 10 percent in SS inflows can have significant effects on sea elevation and salinity. The aforementioned technique maintains the relationships between the historic frequency distributions of both precipitation and evapotranspiration, and not as separate unconnected and constrained variables.
\end{abstract}

\section{Introduction}

The need for improved quantitative precipitation forecasts and realistic assessments of the regional impacts of natural climate variability and climate change has generated increased interest in regional (i.e., systems scale) climate simulation. Because climate warming associated with climate change will exacerbate water sustainability problems, heavily-populated, arid regions such as the Southwest USA are likely to experience some of the highest economic expenses and environmental losses [1]. For example, flows in the Colorado River have been projected to reduce from $10 \%$ to $50 \%$ by midcentury [2]. Other projections indicated that there would be more frequent and longer lasting droughts particularly in the Colorado River Basin in the latter half of the 21st century, suggesting future challenges regarding water supplies throughout southwest [3].

Weather generators can be used to produce synthetic weather sequences (which are time series of random numbers that resemble statistically the observations recorded in nature) and are useful for projecting climate into the future [4]. Most weather generators emphasize precipitation (Prcp) as a primary driving variable of interest and other hydroclimatic variables are either directly or indirectly affected by it [5]; for examples, see weather generator (WGEN) by Richardson and Wright [6], a geospatial-temporal (GiST) weather generator by Baigorria and Jones [7], and/or a two-stage resampling algorithm by Leander and Buishand [8]. Weather generators for simulating hourly Prcp and temperature can also be found, for example, downscaling-disaggregation weather GENerator (DD-WGEN) by Mezghani 
and Hingray [9] and advanced weather GENerator model (AWE-GEN) by Fatichi et al. [5]. Further, Rajagopalan et al. [10] generated Prcp independently with other climate variables, (e.g., solar radiation, temperature) conditioned on the status of Prcp (i.e., rain or no rain on a given day) using a multivariate nonparametric resampling scheme. The other climate variables can then be generated from either independent statistical distributions fitted separately to each of the variables for each of the two Prcp states (i.e., rain or no rain days) [10].

Stochastic weather models are commonly used because they are easy to calibrate, can be implemented quickly, often pertain to daily time scale [11], and can incorporate data from weather generators easily. Wilks [4] used a first-order, twostate Markov process to simulate daily Prcp, basically based on a conditional probability of a wet day following a dry day and a conditional probability of a wet day following a wet day. An assumption of this type of Markov chain model is that the probability of rainfall on any day depends only on whether it rained on the preceding day; however, the proper Markov order to represent the daily Prcp occurrence process cannot be assumed a priori but can only be determined through observational data analysis or via available results of investigation [12].

Most stochastic models of daily rainfall consist of two parts: a model for the occurrence of dry and wet days and a model for the generation of rainfall volume on wet days $[13,14]$. Markov chain models specify each day in a time series as "wet" or "dry," and develop a relationship between the state of the system at time $t$ (e.g., the current day) current day and the states of the preceding days (time $t-1, t-2, \ldots, t-n$ ), where the number of preceding days determines the order of the Markov chain, for example, first order or higher orders [13]. Harrold et al. [15] used four different classes of rainfall amount, categorized according to the number of adjacent wet days whereby the model was conditioned on the rainfall amount of the previous day; this approach accommodates contiguous series of rainfall days (i.e., within-series correlations of rainfall amounts) by using the volume on the previous day as a conditioning variable. Many existing rainfall amount models ignore this correlation structure and assume that the volumes of Prcp at time $t$ are independent of future volumes (i.e., the volume of Prcp at time $t+1$ is independent of the volume occurring at time $t)[15,16]$. However, Buishand [17] and Chapman [13] demonstrated that the distribution of rainfall volumes is different during solitary wet days compared to Prcp occurring over multiple, contiguous days [15]. Srikanthan and Pegram [18] describe a nested multisite daily rainfall stochastic generation model that preserved rainfall characteristics at the daily, monthly, and annual time scales. Srikanthan and Pegram [18] determined that the rainfall volumes on isolated wet days and sequences of wet days did not depend on the duration of the Prcp event as well as they should have.

Evapotranspiration (ETo) changes induced by changing climate conditions are not trivial in hydrologic modeling efforts or water resource management studies [19]. ETo demand is a sensitive parameter that needs to be accounted for; however, often due to limited observational data, it is often implicitly calculated through calibration efforts or mass balance formulation [19].

Although ETo models and procedures for determining ETo exist (e.g., McMahon et al. [20]), ETo is most often calculated based on the results of Prcp and temperature, for example, Beersma and Buishand [21], or in combination with other weather generated variables (e.g., Snyder et al. [22], Wilks [11]). Miller et al. [19] incorporated changing ETo demands with changing temperatures using the variable infiltration and capacity (VIC) model [23] for streamflow projections over the Colorado River headwater basins. More recently, Baigorria [24] simulated daily minimum and maximum temperatures with regard to covariance with rainfall occurrence, that is, max temperatures on rainy days versus nonrainy days. Snyder et al. [22] describe the development of "Simulation of Evapotranspiration of Applied Water" (SIMETAW) application program for helping California plan future water demand for agricultural purposes. SIMETAW uses only monthly averages of total rainfall volume and the number of rain days for simulating daily weather data and requires information for variables associated with a modified version of the Penman-Monteith equation [25].

There is a need to develop more precise methods for simulating Prcp and ETo that account for the natural interdependency of these two processes. This study utilized nonparametric models to determine the statistical relationships between ETo and Prcp, for incorporation of these relationships into hierarchical nested Markov chain models to preserve the interdependent nature of ETo and Prcp fluctuations. We used the Salton Sea (SS) watershed as a case study for our approach for modeling climate futures.

1.1. Study System. The Salton Sea (SS) watershed spans some 8,360 square miles $\left(21,700 \mathrm{~km}^{2}\right)$ in southeastern California and extends from San Bernardino County through Riverside and Imperial counties and into the Mexicali Valley, in Baja California, Mexico [26]. The terminal lake ecosystem of the SS is located in the Colorado Desert $\left(33^{\circ} 15^{\prime} \mathrm{N}, 116^{\circ} \mathrm{W}\right)$ approximately 35 miles $(56 \mathrm{~km})$ north of the US-Mexico border (Figure 1) [27]. The SS is a major hydrologic element of the Lower Colorado River Basin (LCRB) and is considered important to the economic, social, and biological values of the region. However, it is suffering marked degradation as a consequence of human activity and although efforts to rehabilitate the SS ecosystem have been underway for more than a decade, they have had little success.

The present study addresses the need for an integrated systems simulation modeling approach for use in simulating complex water quality and water quantity management policies on both watershed and localized scales. The Salton Sea Stochastic Simulation Model $\left(\mathrm{S}^{4} \mathrm{M}\right)[28]$ is a spatially explicit, stochastic, simulation model, formulated as a differenceequation compartment model with a daily time step using STELLA v. 8.0. software [29] representing water flow (i.e., water volume) and quantity of total dissolved salts (TDS) and phosphorus (P) in the LCRB and SS watershed. Unlike previous models constructed for the SS that relied on datasets consisting mainly of monthly or annual averages, the $S^{4} \mathrm{M}$ 
incorporated a high degree of seasonality and climate forecasting resolution. However, the $S^{4} \mathrm{M}$ initially employed a common technique in modeling the uncertainty in future climate patterns by simply projecting a historic climate data sequence into the future (i.e., deterministic versions of the climate driving variables).

In order to further develop the $S^{4} \mathrm{M}$ with a higher degree of seasonality and climate forecasting resolution, an in-depth analysis was conducted regarding Prcp and ETo for the semiarid region. ETo is one of the less understood components of the hydrologic cycle [30] but is a major component in terrestrial water balance models [31]. Basically, ETo is the sum of the volume of water used by vegetation (transpired), evaporated from the soil and the intercepted Prcp on vegetation $[30,32]$. The difference between evaporation and transpiration is that the latter consists of the vaporization of liquid water contained in plant tissues and the vapor removal to the atmosphere while evaporation occurs at the topsoil if the water is available [30,33].

Located in one of the most arid regions of North America, maximum temperatures around the Salton Sea may exceed $100^{\circ} \mathrm{F}\left(38^{\circ} \mathrm{C}\right)$ more than 110 days each year, while temperatures seldom drop below freezing. Annual Prcp in the region averages less than 3 inches $(7.6 \mathrm{~cm})$, while net evaporation rates from the sea's surface and ETo exceed 66 inches $(175 \mathrm{~cm})$ annually $[27,34]$. For comparison, the Sahara Desert, much like the Colorado Desert surrounding the SS, is characterized by bare soils and large amounts of available energy allowing for any rainfall to quickly return to the atmosphere [35]. Scott et al. [35] observed that the effect of a Prcp event in the Sahara desert environment had a negative effect on evaporation, but the effect rapidly decreased within the first day. Notably, the timescale of soil moisture storage determines the timescale of the ETo persistence and thus the timescale of humidity persistence in the near-surface atmosphere.

Several other models were developed to address sitespecific alternatives for maintaining the Salton Sea. Two hydrodynamic models, RMA-2 and RMA-10, both formulated for the finite element solution method, were applied to simulate the circulation in the sea. This was done to quantify the effects that diked impoundments would have on the sea's circulation and to better understand the sea's circulation via a field monitoring program [36]. Another study conducted a couple of water quality simulations for the $-240^{\prime}$ and $-245^{\prime}$ southern impoundments with the BATHTUB model $[37,38]$. The BATHTUB model uses a series of empirical submodels to predict the annual nutrient budgets and productivity levels in the water body that predicted mean annual water quality in two proposed impoundment configurations [38]. A UC Davis hydrodynamic model of the Salton Sea was used to estimate the effects of changes in sea elevation [39], while Chung et al. [40] developed a linked hydrodynamic and water quality model.

The primary objective of this study was to develop a more precise methodology for generating ETo and Prcp as interdependent stochastic driving variables that can be used in large-scale systems models. A second objective was to implement the stochastic ETo and Prcp driving variables in the $S^{4} \mathrm{M}$ and determine the effects, if any, of a \pm 10 percent change of inflow volumes to the SS, thereby addressing future climate change uncertainty of this critically important watershed.

\section{Methods}

2.1. Determining Statistical Distributions of Historic Data. Following the method of Naoum and Tsanis [30], daily estimates, from 1980 through 2004, of ETo and Prcp were obtained from two meteorological stations [41, 42] in the Salton Sea watershed (Figure 1). Specifically, weather stations in near proximity to the North end and South end of the SS were used, that is, station IDs: Thermal and Indio (TI) and Brawley and Calipatria (BC), respectively. Data points were averaged to get estimates of central tendencies in ETo and Prcp for the SS following methods established in Voinov et al. [43], Bhuyan et al. [44], and Salton Sea Ecosystem Restoration Program [45]. The compiled, averaged 25-year dataset will be henceforth referred to as the averaged dataset.

Daily values of Prcp and ETo data from the averaged weather station data were grouped by month; then each month was tested against thirty-four probability distributions (Table 1) in order to determine the best statistical fit for each month. Monthly distributions were used to preserve seasonality when modeling future climate scenarios, while not solely restricting future climate scenarios to historical values. EasyFit Version 1.3, from MathWave Technologies [46], was used for curve-fitting analyses. The theoretical distribution that provided the "best" fit for each month was determined based on the Kolmogorov-Smirnov (K-S) and Anderson-Darling (A-D) tests of statistical significance, as well as a visual comparison of the fitted curves to the historic frequency distribution.

\subsection{Statistical Models Used to Determine Relationship between} ETo and Prcp. We hypothesized that different durations of Prcp events would have different effects on ETo, and that the ETo volume of a Prcp event at time $t+1$ would depend on the volume (or absence thereof) of Prcp at time $t$. Therefore, individual categories representing single versus multiple Prcp events and corresponding volumes were sorted into subset datasets, along with their respective ETo volumes. In order to thoroughly test these hypotheses, 17 different variables ( 3 continuous, 14 discrete/categorical) were created from the averaged dataset (Table 2). Because the SS is located in an arid region, many of the daily Prcp values are zeros, 90 percent, or more in many cases. As a result of many days without Prcp, the Prcp data exhibited a mixed distribution with a high number of observations having a value of zero and a continuous distribution when there actually were Prcp events. Traditional time series analysis to account for autocorrelation between observations does not handle datasets with such high zero counts, such as those for ETo and Prcp. Therefore, to determine the relationships among Prcp events and between Prcp events and ETo levels, binomial and multinomial logistic regression models were used [47]. Preliminary analyses indicated that the data were 


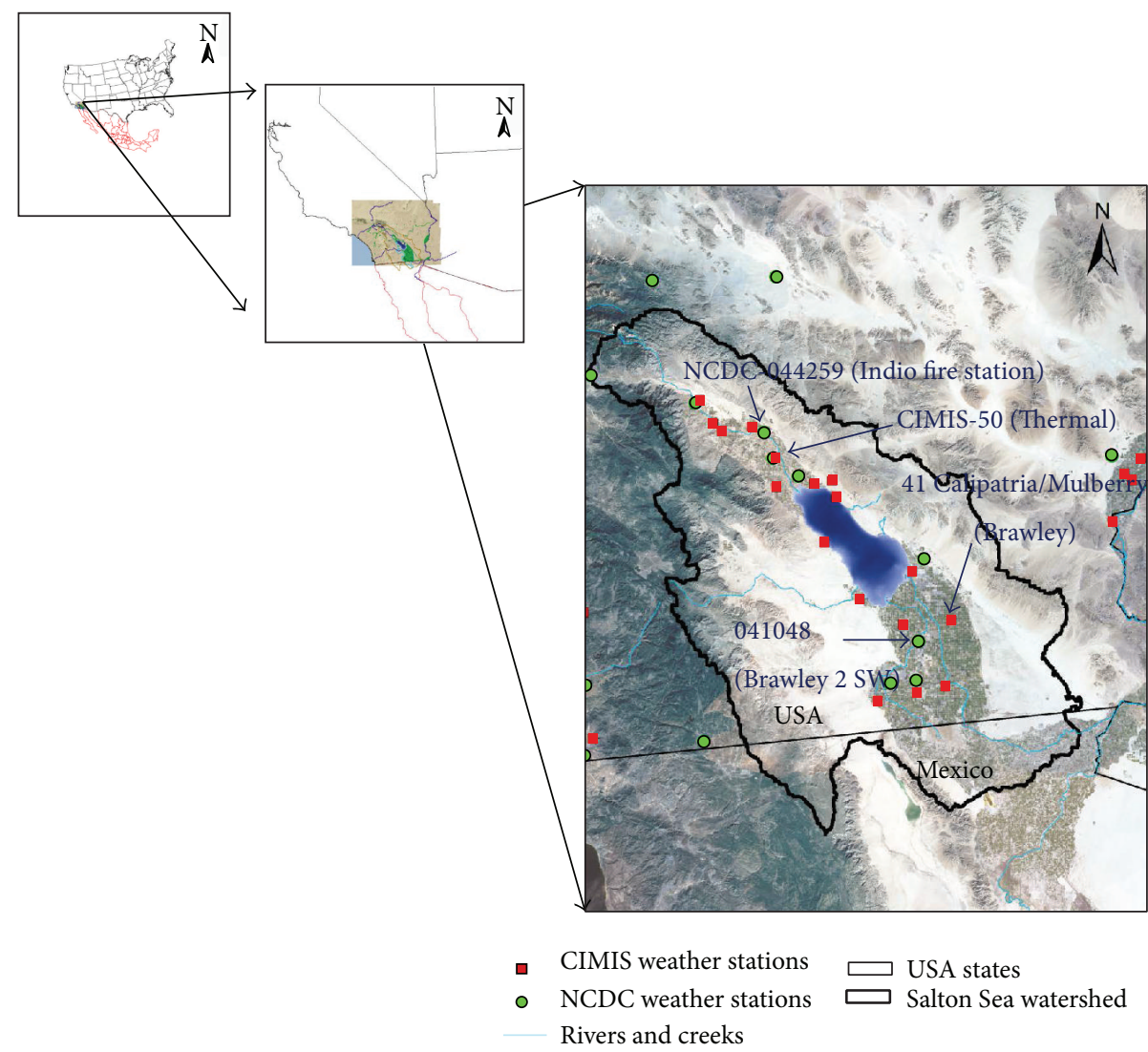

FIGURE 1: Geographic location of the Salton Sea and weather stations within the Salton Sea watershed. Shapefiles were obtained from Redlands Institute, University of Redlands [51].

not overdispersed. From the 17 variables, we developed 16 different statistical models to test the relationship between ETo and Prcp (Table 3). The dependent variables in the logistic regression models were coded as described in Table 2 and tested with binomial or multinomial logistic regression depending on the number of levels [48]. The normality of the standardized residuals, the assumption of linearity in the logit, and a Hosmer-Lemeshow test [48] were used to determine if a model fits the data. A classification table was created using 0.5 as a cut-off point to determine the predictive power of the model, and likelihood ratio tests were used (at $\alpha=0.05$ ) to determine model significance $[47,48]$. Results from the model selection procedure were used as the new, stochastic climate module for the $\mathrm{S}^{4} \mathrm{M}$. Stata Statistical Software v. 9.0. [49] was used for the binomial and multinomial logistic regression statistical analyses.

2.3. Salton Sea Simulation. The $\mathrm{S}^{4} \mathrm{M}$ was constructed to represent water flow in the LCRB as it enters the SS and Colorado River Delta, where it subsequently flows, albeit intermittently, to the Gulf of California. The $S^{4} \mathrm{M}$ specifically accounts for the water volume and water quality in the SS and is formulated as a compartment model based on difference equations with a daily time step using STELLA 8.0 software [29]. ArcGIS v. 9.0. software [50] was utilized for map making, with SS shapefiles obtained from the University of the Redlands Institute [51].

Previously, the strategy used in modeling the uncertainty in future climate patterns in the $S^{4} \mathrm{M}$ consisted of using a deterministic version of the driving variables in which the historic pattern and number of weather events were preserved, that is, the past and present as the future. Using the methodology described above, a stochastic version of the driving variables was implemented and evaluated. This new module was evaluated by comparing observed and simulated data as a means to assess the performance of the simulation model similar to Tong and Chen [52].

In addition, a climate sensitivity analysis was conducted to observe the cumulative effects of \pm 10 percent change of inflow volumes to the SS, if any, on sea elevation and salinity, thereby addressing another aspect of future climate uncertainty. ANOVA and Bonferroni multiple comparisons post hoc tests were performed for SS salinity and elevation variables under both deterministic and stochastic versions of the model using the statistical software SPSS v. 12.0.1. [53].

\section{Results and Discussion}

A comparison of the averaged weather station historic datasets, that is, TIBC datasets, versus the individual weather 
TABle 1: Probability distributions fit to the historical climate datasets.

(1) Beta

(2) Erlang

(3) Erlang (2P)

(4) Error Function

(5) Exponential

(6) Exponential (2P)

(7) Gamma

(8) Gamma (2P)

(9) Gen. Extreme Value

(10) Gen. Logistic

(11) Gen. Pareto

(12) Gumbel Max

(13) Gumbel Min

(14) Inv. Gaussian

(15) Inv. Gaussian (2P)

(16) Laplace

(17) Logistic

(18) Lognormal

(19) Lognormal (2P)

(20) Normal

(21) Pert

(22) Phased Bi-Exponential

(23) Phased Bi-Weibull

(24) Rayleigh

(25) Rayleigh (2P)

(26) Triangular

(27) Uniform

(28) Wakeby

(29) Weibull

(30) Weibull (2P)

(31) Chi-Squared

(32) Chi-Squared (2P)

(33) Pareto

(34) Student's $t$

station historic datasets was made for both Prcp and ETo. The TIBC monthly datasets preserved seasonality for both Prcp and ETo as illustrated in the figures (Figures 2-4).

Notably, for the months of February, March, and April the average monthly Prcp volume was lower than the actual weather station historic data. This occurred for two reasons: (1) the disparity in the number of observations between the two weather station datasets and the average resulting in the largest number of observations between the two, and (2) the concomitant decrease in values due to averaging, for example, one weather station having a higher Prcp volume on a given day and the other having a much lower value for the respective day. Instances of missing data in the $\mathrm{BC}$ dataset required the replacement of the missing data with TI weather station values, and in such cases, often with a volume of 0 due to the high frequency of days without Prcp events.
The averaging of the weather station data for both Prcp and ETo provided a complete dataset for a 25 -year period (1980-2004) for the SS area. Although the pattern of monthly Prcp volumes was preserved when the two separate whether station datasets were averaged, the frequency of Prcp events of a given duration was somewhat inflated. More specifically, the averaging increased the number of consecutive Prcp events when comparing the $\mathrm{BC}$ dataset, having a maximum of 7 consecutive events and the TI dataset having a maximum of 9 consecutive events with the TIBC averaged dataset having a maximum of 10 consecutive events. The frequency of smaller events was inflated as well. For example, Prcp events of five or more days in duration were as follows: BC with 7 instances, TI with 13 instances, and the TIBC averaged dataset with 36 instances. Similarly, events of 8 days in duration or more were as follows: $\mathrm{BC}$ with 0 instances, TI with 3 instances, and the TIBC averaged dataset with 8 instances. As a result, some months in the TIBC averaged dataset experienced inflated Prcp event durations more than others, for example, January, September, and December. Therefore, the BC weather station dataset statistical relationships, concerning subsequent Prcp events, were implemented and not those based on the averaged dataset. The aforementioned strategy was undertaken as a means to avoid the inflated frequencies of multiple Prcp events being incorporated into the simulation model. The inflated values demonstrate the potential for introduced error in modeling when using averaged data.

3.1. Determining Statistical Distributions of Historic Data. Graphs of the curve fitting results based on the historic frequency distributions for both Prcp and ETo provided a visual aid for determining which theoretic probability distribution gave the "best" fit. The curve providing the "best" fit and associated levels of significance ( $P$-value) for the Kolmogorov-Smirnov (K-S) and Anderson-Darling (A-D) test statistics were recorded for each weather station dataset as well as the TIBC averaged dataset. The results of the two test statistics differed at times, that is, listing two different curves as providing the "best" fit. In the aforementioned situation, a final decision pertaining to the "best" fit was made based on a visual assessment of the figures. A summary of the overall curve fitting results can be found in Kjelland [28].

The curve-fitting exercise resulted in similar distributions providing the "best" fit to the data; however, the distribution for the TIBC averaged dataset for days of individual months often varied, more so in the case of ETo than for Prcp. For example, the most common distribution type providing the "best" fit for both the BC and TI ETo datasets was a Wakeby distribution, but the TIBC averaged dataset (average of the two) more closely resembled Wakeby, General Logistic, and General Extreme Value distributions, depending upon the month in question. The most common distribution types providing the "best" fit for both BC and TI Prcp monthly datasets were Gamma and Exponential distributions, but the TIBC averaged dataset more often resembled Gamma and Rayleigh distributions. The aforementioned differences demonstrate some of the compromises as a result of averaging the datasets. 
TABLE 2: Description of variables used for the statistical analyses. Note that event refers to days in which precipitation occurred, either as a one day occurrence or as multiple contiguous days.

\begin{tabular}{|c|c|c|c|}
\hline Name & Description & Type of variable & Description of levels \\
\hline Prcp & Daily historic precipitation & Continuous & Daily values from 1982 to 2004 \\
\hline ETo & Daily historic evapotranspiration & Continuous & Daily values from 1982 to 2004 \\
\hline Month & Month of year & Discrete (12 levels) & $1=$ January, 2 = Feb., ..., 12 = Dec. \\
\hline RainEvent & Presence or absence of Prcp event & Discrete (binary) & $0=$ absent, $1=$ present \\
\hline ETo $\leq 0.21^{\prime \prime}$ & Did ETo exceed $0.21^{\prime \prime} ?$ & Discrete (binary) & $0=$ true, $1=$ false \\
\hline CatEvent & $\begin{array}{l}\text { Number of consecutive days of } \\
\text { precipitation }\end{array}$ & Discrete (7 levels) & $\begin{array}{l}0=\text { no prcp, } 1=\text { one day of prcp, } \ldots, 7=\text { seven } \\
\text { consecutive days of prcp }\end{array}$ \\
\hline CatVol & $\begin{array}{l}\text { Comparison between volumes }(v) \text { of } \\
\text { precipitation between subsequent time } \\
\text { steps (i.e., comparing events at time } t \text { to } \\
\text { events at time } t+1 \text { ) }\end{array}$ & Discrete (5 levels) & $\begin{array}{l}0=\text { no prcp } \\
1=\text { single event (a prcp event not followed by } \\
\text { another) } \\
\begin{array}{l}2=E_{v, t}<E_{v, t+1} \\
3=E_{v, t}=E_{v, t+1} \\
4=E_{v, t}>E_{v, t+1}\end{array}\end{array}$ \\
\hline PrcpAmt & Amount of precipitation per event & Discrete (5 levels) & $\begin{array}{l}0=\text { no Prcp } \\
1=\operatorname{Prcp} \leq 0.1^{\prime \prime} \\
2=0.1^{\prime \prime}<\operatorname{Prcp} \leq 0.2^{\prime \prime} \\
3=0.2^{\prime \prime}<\operatorname{Prcp} \leq 0.5^{\prime \prime} \\
4=0.5^{\prime \prime}<\operatorname{Prcp}\end{array}$ \\
\hline Prcponafter & $\begin{array}{l}\text { Denotes first day of event or day after } \\
\text { event }\end{array}$ & Discrete (3 levels) & $\begin{array}{l}1=\text { for first day of prcp event, } 2=\text { day after } \\
\text { event, } 0=\text { all other days }\end{array}$ \\
\hline Prcpbefafter & $\begin{array}{l}\text { Denotes day before event or day after } \\
\text { event }\end{array}$ & Discrete (3 levels) & $\begin{array}{l}1=\text { for day preceding prcp event, } 2=\text { day } \\
\text { immediately after event, } 0=\text { all other days }\end{array}$ \\
\hline PrcpOn & Denotes first day of event & Discrete (binary) & $\begin{array}{l}1=\text { first day in series of prcp event, } 0=\text { all other } \\
\text { days }\end{array}$ \\
\hline EToAmt & Amount of ETo per event & Discrete (6 levels) & $\begin{array}{l}0=\mathrm{ETo} \leq 0.11 \\
1=0.11<\text { ETo } \leq 0.21 \\
2=0.21<\mathrm{ETo} \leq 0.32 \\
3=0.32<\mathrm{ETo} \leq 0.41 \\
4=0.41<\text { ETo } \leq 0.5 \\
5=0.5<\text { ETo }\end{array}$ \\
\hline EToPerCh & $\begin{array}{l}\text { Percent change in ETo from one time step } \\
\text { to next }\end{array}$ & Continuous & \\
\hline EToFirst & $\begin{array}{l}\text { Compares ETo on day before event to } \\
\text { ETo on day of event }\end{array}$ & Discrete (4 levels) & $\begin{array}{l}0=\text { no prcp or a consecutive day } \\
1=\text { ETo before prcp event }<\text { ETo on day of event } \\
2=\text { ETo before prcp event }=\text { ETo on day of event } \\
3=\text { ETo before prcp event }>\text { ETo on day of event }\end{array}$ \\
\hline ETolev2 & $\begin{array}{l}\text { Compares ETo on day of event to ETo on } \\
\text { day after event }\end{array}$ & Discrete (4 levels) & $\begin{array}{l}0=\text { no prcp } \\
1=\text { ETo after prcp event }<\text { ETo on day of event } \\
2=\text { ETo after prcp event }=\text { ETo on day of event } \\
3=\text { ETo after prcp event }>\text { ETo on day of event }\end{array}$ \\
\hline EToOne & $\begin{array}{l}\text { Compares ETo on day before an event to } \\
\text { ETo on day after event }\end{array}$ & Discrete (4 levels) & $\begin{array}{l}0=\text { no prcp or a consecutive day } \\
1=\text { ETo on day after event }<\text { ETo day before } \\
\text { event } \\
2=\text { ETo on day after event }=\text { ETo day before } \\
\text { event } \\
3=\text { ETo on day after event }>\text { ETo day before } \\
\text { event }\end{array}$ \\
\hline
\end{tabular}


TABLE 2: Continued.

\begin{tabular}{|c|c|c|c|}
\hline Name & Description & Type of variable & Description of levels \\
\hline \multirow{4}{*}{ EToTwo } & \multirow{4}{*}{$\begin{array}{l}\text { Compares ETo of first day of an event to } \\
\text { ETo on day after event }\end{array}$} & \multirow{4}{*}{ Discrete (4 levels) } & $0=$ no prcp or a consecutive day \\
\hline & & & $\begin{array}{l}1=\text { ETo on day after event }<\text { ETo on first day of } \\
\text { event }\end{array}$ \\
\hline & & & $\begin{array}{l}2=\text { ETo on day after event }=\text { ETo on first day of } \\
\text { event }\end{array}$ \\
\hline & & & $\begin{array}{l}3=\text { ETo on day after event }>\text { ETo on first day of } \\
\text { event }\end{array}$ \\
\hline
\end{tabular}

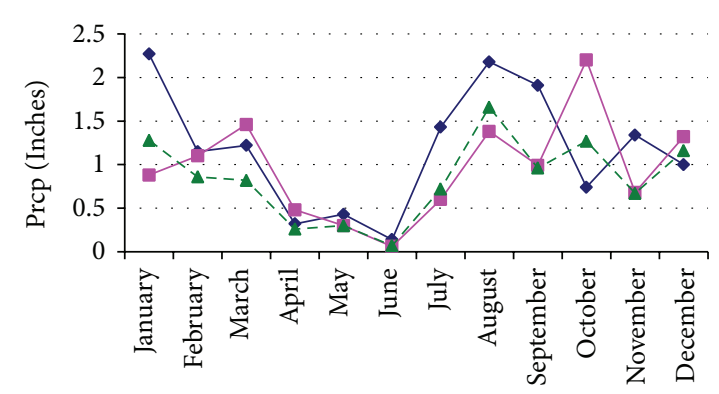

Month

(a)

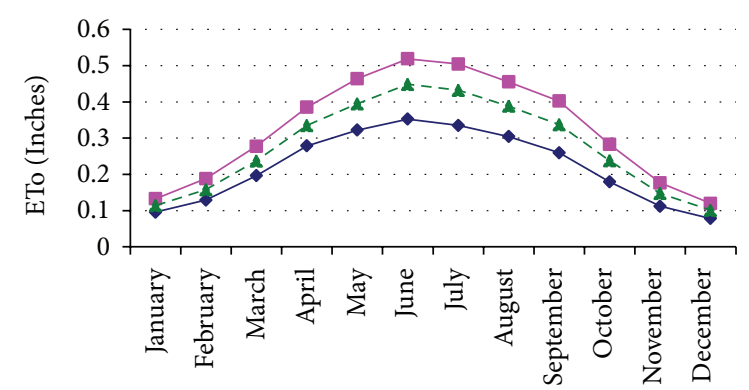

Month

(b)

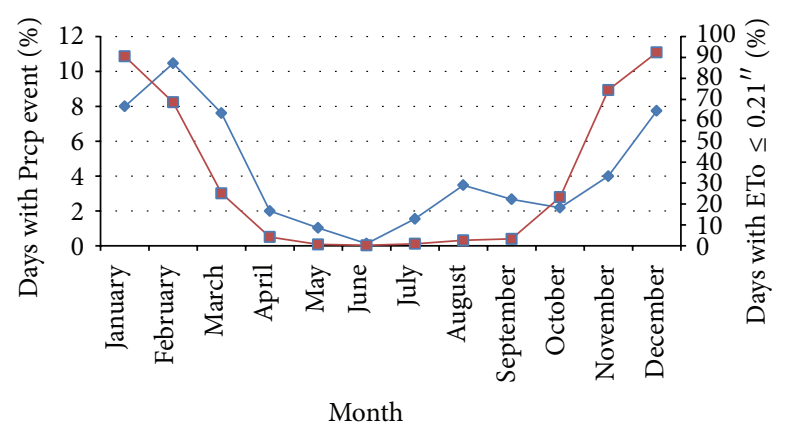

(c)

Figure 2: (a) Maximum precipitation (Prcp) volumes by month for each weather station (diamond markers = Thermal-Indio $(\mathrm{TI})$, square markers $=$ Brawley-Calipatria (BC) ) and their combined average (dashed line). (b) Comparison of mean evapotranspiration (ETo) by month for each weather station (diamond markers $=\mathrm{TI}$, square markers $=\mathrm{BC}$ ) and their combined average (dashed line). (c) Monthly comparison of precipitation (Prcp) event days and days having evapotranspiration (ETo) $\leq 0.21$ inches based on the BC weather station dataset (1982-2004). RainEvent $($ Prcp event $)=$ percent of observations having some amount of Prcp, that is, a Prcp event, ETo $\leq 0.21=$ percent of observations having ETo $\leq 0.21$ inches.

3.2. Statistical Models Used to Determine Relationship between ETo and Prcp. It was hypothesized that Prcp and ETo would generally exhibit a negative relationship in the area surrounding the SS, that is, ETo volumes decreasing with Prcp events. Also, the volume and duration of Prcp events would be important factors to consider when exploring any relationship between Prcp and ETo. The two logistic regression models (Equations (1) and (2)) in Table 3 established that some months were significantly different than others concerning the amounts of Prcp and ETo.

The negative relationship between Prcp and ETo was tested statistically using two multinomial logistic regression models and one binomial logistic (logit) regression model (Equations (3), (4) and (5)), respectively (Table 3). The logit model (Equation (3)) resulted in negative coefficients $(P<$
0.05) for all four categories of "PrcpAmt" and had a Prob $>\chi^{2}$ of $<0.0001$ and Pseudo $R^{2}$ of 0.105. A likelihood-ratio test for independent variables resulted in a $\chi^{2}$ of 382.6 and Prob $>\chi^{2}$ of $<0.0001$. Similarly, the logit model (Equation (4)) resulted in negative coefficients $(P<0.05)$, with an increasing trend, for all five categories of "CatEvent" and had a Prob $>\chi^{2}$ of $<0.0001$ and Pseudo $R^{2}$ of 0.124 . Also, a likelihood-ratio test for independent variables resulted in a $\chi^{2}$ of 439.9 and Prob $>\chi^{2}$ of $<0.0001$. The logit model (Equation (5)) resulted in a statistically significant $(P<0.05)$ and negative coefficient for the variable ETo and an overall Pseudo $R^{2}$ of 0.131 .

The relationship between the volume of a single Prcp event and subsequent Prcp event volumes and associated changes in ETo was tested statistically using the logit model 
TABLE 3: Equations used to test the relationship among seasonality, precipitation, and evapotranspiration. All equations were modeled using the logit link (i.e., logistic equations, Agresti, 1996 [47]).

\begin{tabular}{ll}
\hline Equation \# & Equation \\
\hline$(1)$ & Month $=\alpha+\beta *$ Prcp \\
$(2)$ & Month $=\alpha+\beta *$ ETo \\
$(3)$ & PrcpAmt $=\alpha+\beta *$ ETo \\
$(4)$ & CatEvent $=\alpha+\beta *$ ETo \\
$(5)$ & RainEvent $=\alpha+\beta *$ ETo \\
$(6)$ & CatVol $=\alpha+\beta *$ ETo \\
$(7)$ & EToFirst $=\alpha+\beta *$ PrcpAmt \\
$(8)$ & EToFirst $=\alpha+\beta *$ ETo \\
$(9)$ & ETolev2 $=\alpha+\beta *$ PrcpAmt $+\beta_{2} *$ CatEvent \\
$(10)$ & ETolev2 $=\alpha+\beta *$ ETo \\
$(11)$ & ETolev2 $=\alpha+\beta *$ PrcpAmt $+\beta_{2} *$ CatVol $+\beta_{3} *$ CatEvent $+\beta_{4} *$ Month \\
$(12)$ & Prcponafter $=\alpha+\beta *$ ETo \\
$(13)$ & Prcponafter $=\alpha+\beta *$ EToPerCh \\
$(14)$ & Prcpbefafter $=\alpha+\beta *$ ETo \\
$(15)$ & Prcpbefafter $=\alpha+\beta *$ EToPerCh \\
$(16)$ & PrcpOn $=\alpha+\beta *$ EToPerCh \\
\hline
\end{tabular}

(Equation (6)) in Table 3. The model resulted in negative coefficients for all four categories of "CatVol" and had a Prob $>\chi^{2}$ of $<0.0001$ and Pseudo $R^{2}$ of 0.123 . The categories 1,2 , and 4 of the nominal categorical variable "CatVol" were significant $(P<0.05)$. Also, a likelihood-ratio test for independent variables resulted in a $\chi^{2}$ of 433.236 and Prob $>\chi^{2}$ of $<0.0001$.

The relationship between different Prcp volumes and associated changes in ETo before a Prcp event and the day of a Prcp event was tested statistically using the logit model (Equation (7)) in Table 3. The model resulted in statistically significant $(P<0.05)$ positive coefficients for categories 1 , 2 , and 3 of "EToFirst" (using category 0 as the base outcome) and had a Prob $>\chi^{2}$ of $<0.0001$ and Pseudo $R^{2}$ of 0.423 . Also, a likelihood-ratio test for independent variables resulted in a $\chi^{2}$ of 1026.596 and $P>\chi^{2}$ of $<0.0001$. Another logit model, (Equation (8)) in Table 3, showed that the categories of 1,2 , and 3 of the dependent nominal categorical variable "EToFirst" were less than the base outcome, as all had negative and significant $(P<0.05)$ coefficients.

The relationship between ETo the day of a Prcp event (or the first day in a series of events) and the day after the event (or series of events) was tested statistically using the logit models (Equations (9)-(13)) in Table 3. The logit model (Equation (9)) resulted in positive coefficients $(P<0.05)$ for categories 1, 2, and 3 of "ETolev2," for both independent variables and had a Prob $>\chi^{2}$ of $<0.0001$ and Pseudo $R^{2}$ of 0.494 . Also, a likelihood-ratio test for independent variables resulted in a $\chi^{2}$ of 82.876 for "PrcpAmt" and 317.128 for "CatEvent" and both had a $P>\chi^{2}$ of $<0.0001$. Another logit model, (Equation (10)) in Table 3, showed that "ETolev2" categories 1, 2, and 3 all had negative coefficients, although category 1 was not significant, $P>0.05$. Two additional variables to measure the effect of month ("Month") and the respective comparisons of Prcp volumes ("CatVol") associated with single versus subsequent Prcp events were included in another logit model (Equation (11)) in Table 3. The aforementioned model resulted in some negative coefficients for the independent variables of "CatVol" and "Month" but not "PrcpAmt" and "CatEvent" and had a Prob $>\chi^{2}$ of $<0.0001$ and Pseudo $R^{2}$ of 0.495 . The independent variables "CatVol" and "Month" were not significant $(P>0.05)$ for any of the three categories of the dependent nominal categorical variable "ETolev2." A likelihood-ratio test for independent variables resulted in a $\chi^{2}$ of 1.541 for "CatVol" and 0.906 for "Month" and Prob $>\chi^{2}$ of 0.673 and 0.824 , respectively. Models (Equations (12) and (13)) in Table 3, measuring the relationship between Prcp and ETo and the percent change in ETo the day of the event, as compared to after the event, both had statistically significant $(P<0.05)$ and negative coefficients and a Pseudo $R^{2}$ of 0.061 and 0.024 , respectively.

The relationship between ETo the day before a Prcp event (or sequence of Prcp events) was tested statistically using the logit model (Equation (14)) in Table 3. The logit model (Equation (14)) measuring the relationship between Prcp and ETo before the day of the event had statistically significant $(P<0.05)$ and negative coefficients and a Pseudo $R^{2}$ of 0.038 .

The relationship between ETo the day after a Prcp event (or after the last Prcp event in the sequence) was tested statistically using the logit model (Equation (15)) in Table 3. The logit model (Equation (15)) measuring the percent change in ETo after the Prcp event had a Pseudo $R^{2}$ of 0.016 with positive coefficients for the independent variables. Category 2 of the dependent nominal categorical variable "Prcpbefafter" was statistically significant $(P<0.05)$ whereas category 1 was not $(P=0.802)$.

The general relationship between ETo the day of the first Prcp event (or the first day in a series of events) compared to days without Prcp (or days having Prcp events that are not the first day in the series of events) was tested statistically using the logit model (Equation (16)) in Table 3. The model resulted 


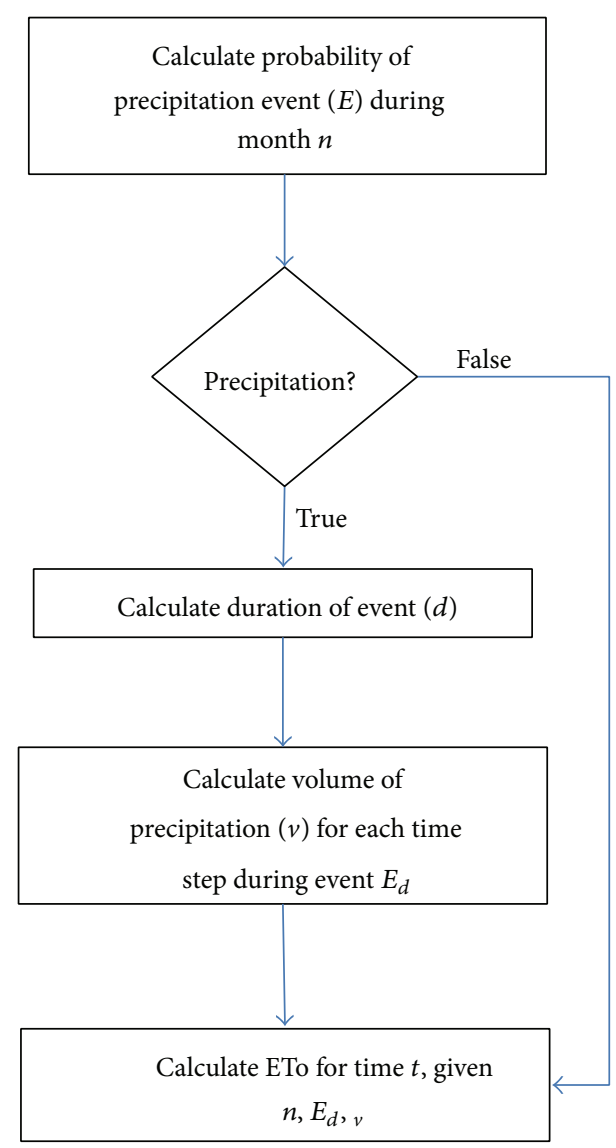

FIGURE 3: Simulation model sampling method for evapotranspiration and precipitation.

in a statistically significant $(P<0.05)$ negative coefficient and had a Prob $>\chi^{2}$ of $<0.0001$ and Pseudo $R^{2}$ of 0.015 .

The Prcp data in this study demonstrated that the majority of the rainfall occurred during the winter months. Also, months with a higher percentage of Prcp events had a larger percentage of days with low (0.21 inches or less) ETo (Figure 2(c)). And like the study by Scott et al. [35], where the effect of a Prcp event in the Sahara desert environment had a negative effect on evaporation, the results herein indicated that the same was true for ETo in the semiarid environment around the SS. However, unlike the results of Scott et al. [35] that showed the effect of a Prcp event on evaporation rapidly decreasing within the first day, the results of the present study elucidate a more complex relationship.

There are two important variables that play a role in the relationship between Prcp and ETo amounts, namely, duration ("CatEvent") and volume ("PrcpAmt"). The results demonstrate that a longer Prcp event is more likely to suppress ETo volumes and for a longer time period. Likewise, larger Prcp volumes suppress ETo volumes more so than the small Prcp volume events; however, larger Prcp volume events also tend to have a higher proportion of the largest ETo volumes compared to small Prcp events. Therefore, the variable "CatEvent" would seem to be a better predictor of
ETo volumes, and the multinomial logistic regression models support this.

The chances of a decrease in ETo the day of a Prcp event compared to the day before the Prcp event were twice as likely (62 percent) than ETo increasing the day of the Prcp event (31 percent). Further, lower Prcp amounts had a slightly higher probability (42 and 43 percent, resp.) for categories 1 and 2 of the ordinal categorical variable "PrcpAmt" versus (35 and 29 percent, resp.) for categories 3 and 4. The probability of ETo more than the day before the Prcp event increased for category 4 of "PrcpAmt" (32 percent) versus (29 percent) for categories 3 and 1, respectively, of the variable "EToFirst." The overall negative effect of Prcp on ETo levels was supported by Equations (3)-(5) respectively, showing statistically significant $(P<0.05)$ and negative coefficients for all categories of "PrcpAmt," "CatEvent," and "RainEvent." Compared to days without Prcp events, days with Prcp events had significantly lower ETo volumes. Similarly, all categories of the ordinal categorical variable "CatEvent" measuring duration of Prcp events had statistically significant $(P<0.05)$ negative coefficients and showed that the longer the duration of the Prcp event, the larger the decrease in ETo levels, in general. Also, the Pseudo $R^{2}$ was somewhat larger for the variable "CatEvent" versus "PrcpAmt" (0.124 versus 0.105 , resp.) meaning that the duration of the Prcp event was a slightly better predictor of the decrease in ETo volumes. The nominal categorical variable "CatVol" distinguished between a single or subsequent Prcp event taking into account volume and supported these conclusions based on the logit model (Equation (6)).

The logit model (Equation (8)) with the dependent nominal categorical variable "EToFirst" measured whether ETo the day of a Prcp event was less than, equal to, or greater than before the Prcp event. The logit model (Equation (8)) demonstrated that ETo volumes the day of a Prcp event were significantly less than ETo volumes on days without Prcp. Further, the plot of the Prcp and ETo observations by month (Figure 2) revealed that months with a higher percentage of rain days also had a higher percentage of days with ETo $\leq 0.21$ inches. ETo and Prcp exhibited a negative relationship overall, as initially hypothesized.

When observing recovery time using the nominal categorical variable "ETolev2" (Equations (9)-(11)) measuring whether ETo is the same after a Prcp event (or the last event in the series of events) as during a Prcp event (or the last day of Prcp in the series of events), there was a greater likelihood of ETo increasing the day after the Prcp event or series of events versus decreasing ( 38 versus 21 percent, resp.). The greater likelihood of ETo increasing the day after the Prcp event (or series of events), versus decreasing, was also the case for events lasting more than one day, for example, 13 versus 59 percent (resp.) for two-day events. The recovery time or increase in ETo after the Prcp event was more likely with lower Prcp volumes than for higher Prcp volumes, for example, 50 percent for category 1 versus 29 percent for category 4 of the dependent variable "PrcpAmt." Also, the logit model (Equation (16)) with the dependent nominal categorical variable "PrcpOn" showed a negative change in ETo on the day of a Prcp event, or first day in a series of events 


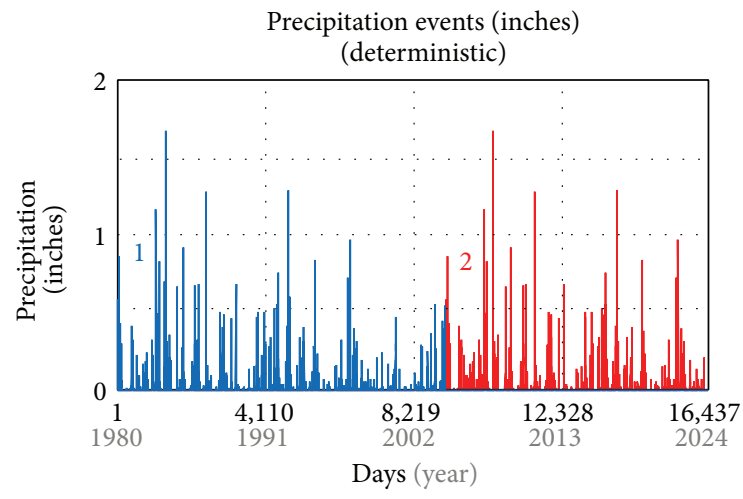

(a)

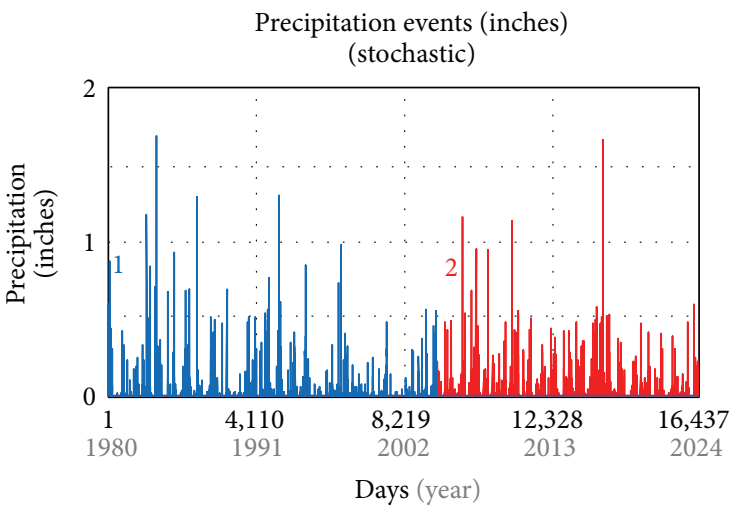

(c)

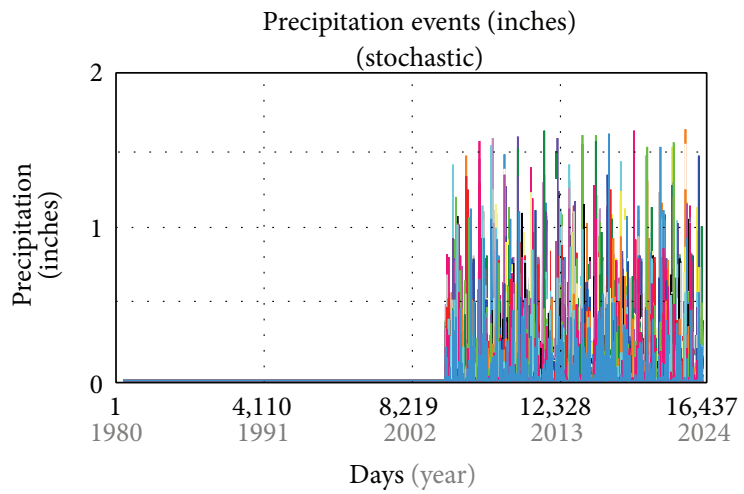

(e)

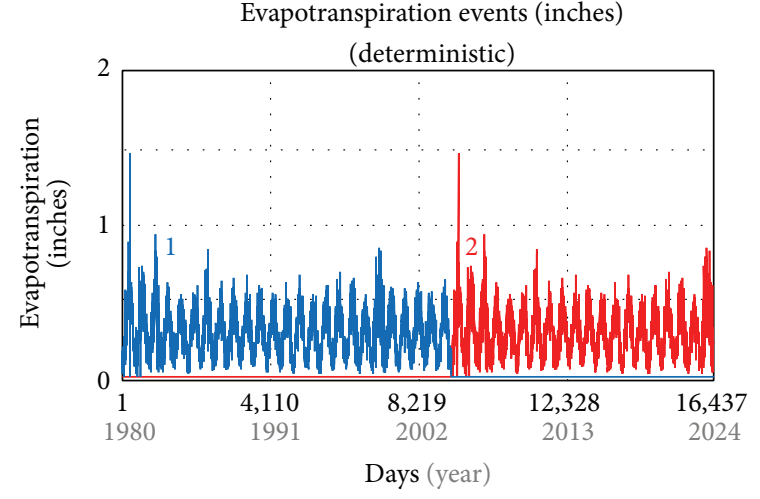

(b)

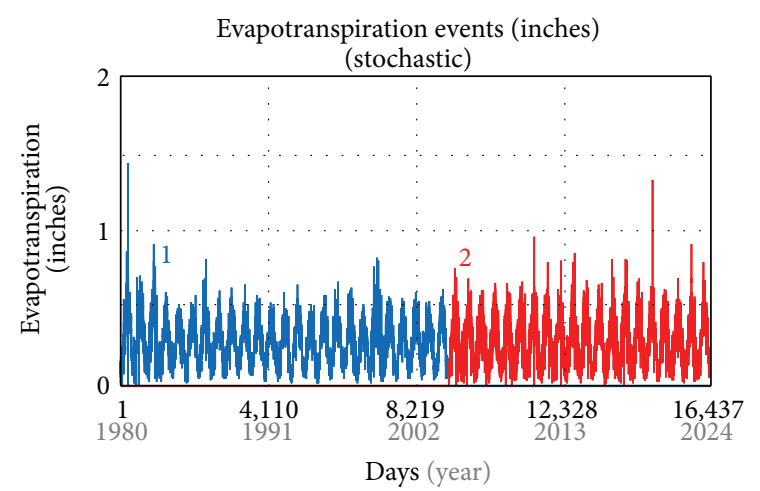

(d)

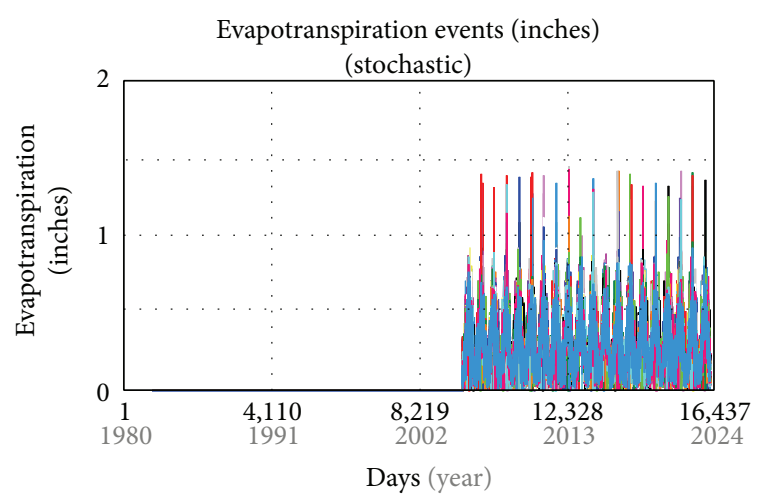

(f)

Figure 4: Comparison of historic (1) versus simulated (2) and deterministic versus stochastic climates for the $\mathrm{S}^{4} \mathrm{M}$ daily time step: (a) precipitation (Prcp) events (inches) - simulated deterministic, (b) evapotranspiration (ETo) events (inches) - simulated deterministic, (c) Prcp events (inches) - simulated stochastic, (d) ETo events (inches) — simulated stochastic, (e) Prcp events (inches) — simulated stochastic (100 repetitions), and (f) ETo events (inches) - simulated stochastic (100 repetitions).

when compared to days without Prcp events. Moreover, the logit model (Equation (12)) with the dependent nominal categorical variable "Prcponafter" showed that compared to days without Prcp, the first day of a Prcp event produced a lower ETo volume (coefficient of -5.842) while days after a Prcp event (or the last day in a series of events) also had a lower ETo volume (coefficient of -4.624). Clearly, the first day of the Prcp event had a larger ETo volume than the day after the Prcp event (or series of events) indicating some recovery from the Prcp event. The recovery time of ETo was tested using another logit model (Equation (13)) using the same dependent variable "Prcponafter" but with the independent variable "EToPerCh," measuring the percent change in ETo from one day to the next. The logit model (Equation (13)) results showed that when compared to days without Prcp, ETo decreased on the first day of a Prcp event. However, a positive 
change in ETo the day after the Prcp event (or the last day in a series of events) means ETo increased when compared to days without Prcp events.

An analysis of the frequency of observations for each category of the variable "EToOne" showed that ETo the day after a sequence of Prcp events is generally less than the ETo the day before the sequence of Prcp events. In fact, the ETo volume after the Prcp event is less than the ETo volume the day before the first Prcp events 48 and 50 percent of the time for larger Prcp volume events. Therefore, the frequency that recovery time is within a day of a Prcp event only occurs about 50 percent of the time for larger volume Prcp events.

The logit model (Equation (14)) demonstrated that there is actually less ETo the day before a Prcp event as compared to days without Prcp. Moreover, compared to days without Prcp there is typically less ETo the day after the Prcp event, or last day in a series of events. The other logit model (Equation (15)) reveals a positive increase in ETo before a Prcp event and a positive increase the day after a Prcp event (or series of events) when compared to days without Prcp events. The analysis of single versus subsequent Prcp events result showed the probability of a given Prcp volume for a second consecutive Prcp event based on the Prcp volume of the first Prcp event.

3.3. Salton Sea Stochastic Simulation Model $\left(S^{4} M\right)$. Based on the complex relationships revealed by the logistic regression models, a methodology to generate ETo and Prcp as driving variables in a simulation model other than using the historic data time series (in other words not copying the historic data time series and pasting it to represent the future data time series) was developed for ETo and Prcp data within the SS watershed. However, the technique used in this study maintains the relationships between the historic frequency distributions and interdependency of ETo and Prcp (Figure 2), instead of treating them as separate unconnected variables in the model. Curves for statistical distribution curves were fit to the historical ETo and Prcp data for the occurrence of a precipitation event, the duration of an event, the volume of the event, and the volume of evapotranspiration occurring on that day. The simulation processes the new module following the logic in Figure 3. For any time step for a given month, there are four steps: (1) the probability of a Prcp event occurring is randomly selected from the statistical distribution for that month; (2) if Prcp occurs, then a duration of the event is chosen from the probability distribution of durations for that month (with maximum durations being 7 days); (3) a volume of Prcp is calculated from the probability distributions of volumes for events of that duration for that month; and (4) ETo is generated from the probability distributions associated with Prcp events of that duration for that month (Figure 3). The ability of the $S^{4} \mathrm{M}$ to reasonably simulate the fluctuations in Prcp and ETo volumes, duration of Prcp events, all while preserving the relationships between the patterns between them is evident in Figure 4.

3.4. $S^{4} M$ Evaluation. The deterministic version of $S^{4} M$ was evaluated in Kjelland [28]. When the stochastic weather simulator was added, the model simulated historic sea elevations reasonably well with a difference of only 1 foot at its most disparate point, -228 fasl (simulated) and -229 fasl (historic), and maintained patterns of seasonality. Based on the observed versus simulated sea elevation data, the model has an error rate of less than $1 \%$. These sea elevation results are comparable to IIDWD and CH2MHILL [54], indicating that $S^{4} \mathrm{M}$ has a reasonable ability to simulate the hydrology of the Salton Sea. Figure 4 shows that Prcp and ETo and patterns are similar when comparing the simulated versus historic data, in both magnitude, that is, volumes, and frequency. With regard to TDS, the model validation simulations resulted in the most disparate underestimation of $2,999 \mathrm{mg} / \mathrm{L}(44,788 \mathrm{mg} / \mathrm{L}$ simulated versus $47,787 \mathrm{mg} / \mathrm{L}$ observed) compared to the most disparate overestimation of $2,541 \mathrm{mg} / \mathrm{L}(42,963 \mathrm{mg} / \mathrm{L}$ simulated versus $40,422 \mathrm{mg} / \mathrm{L}$ observed). Based on the observed versus simulated sea TDS data, the model has an error rate of about $7 \%$ at its most disparate points and can be regarded as reasonable given that subsequent years' error rates are much less and the sea's general salinity trend does not change. The model verification results for salinity in a study by IIDWD and CH2MHILL [54] yielded an error rate of approximately $6 \%$ at the most disparate point (1980 to 2000), similar to results of the Salton Sea Ecosystem Restoration Program [55].

The $\mathrm{S}^{4} \mathrm{M}$ results pertaining to the baseline trends in elevation and salinity projections for the year 2024 are similar to the results from other studies. For example, the Colorado River Board of California [56] used sequential cycling of historic conditions as the basis for future inflow conditions and estimated Salton Sea elevations from approximately -231.4 to -233 fasl and a salinity of 67,000 to $79,600 \mathrm{ppm}$ by the year 2020. Cohen and Hyun [27] showed a Salton Sea elevation of -233.6 fasl and a salinity of 60,000 ppm by the year 2018, and an elevation of approximately -245 fasl with salinity between 90,000 and 100,000 ppm by the year 2024 . The simulated Salton Sea elevation and salinity results were -234 fasl and 75,000 ppm, respectively, by the year 2030 and assumed reduced future inflow conditions [39]. Moreover, current conditions show that model simulations for salinity are very similar to those of today, about 48,055 ppm (48 g/L) [57] to about 51,000 ppm (approximately $51 \mathrm{~g} / \mathrm{L}$ ) [58].

\subsection{Salton Sea Climate Scenarios Using Stochastic Generator.} Three future SS climate scenarios were examined: (1) no change in ETo, Prcp, and river flows (Baseline) versus (2) a scenario of a ten percent increase in Prcp and river flows, and (3) a scenario of a 10 percent decrease in Prcp and river flows (most likely scenario according to Seager et al. [59]). In the climate sensitivity analysis using the historic driving variables ETo, Prcp, and river flows, that is, the past projected into the future version of the model, the elevation of the sea at the end of 2024 was -235.38 fasl with a salinity of $59,292 \mathrm{mg} / \mathrm{L}$ under baseline conditions versus -233.38 and -237.09 fasl and salinities of 56,533 and 61,903 mg/L for scenarios 2 and 3 , respectively (Figure 5, Table 4). In the stochastic version of the model, the elevation of the sea at the end of 2024 was -235.36 fasl with a salinity of $59,025 \mathrm{mg} / \mathrm{L}$ for the baseline 


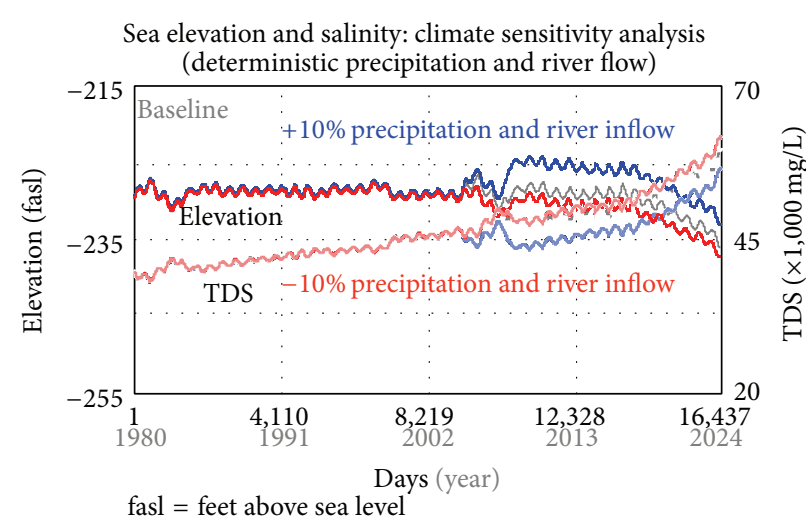

(a)

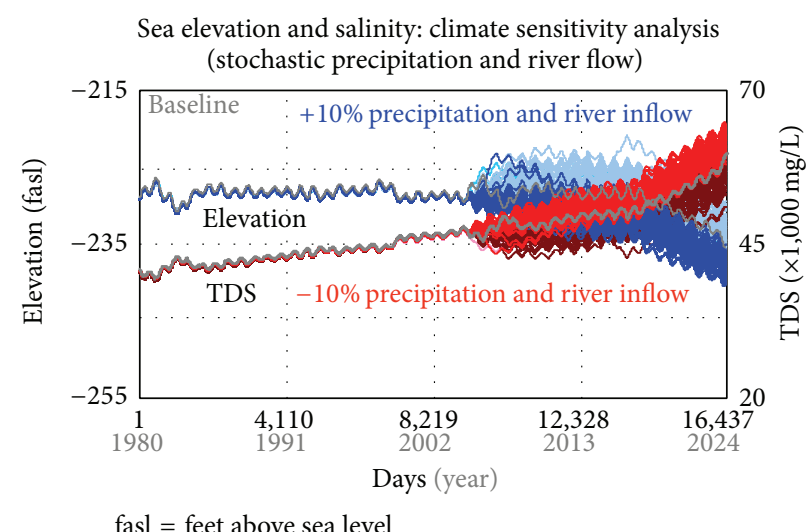

(b)

Figure 5: Salton Sea Stochastic Simulation Model $\left(S^{4} \mathrm{M}\right)$ climate sensitivity analysis: (a) climate sensitivity analysis ( $\pm 10 \%$ historic) using deterministic driving variables (100 replicates) and (b) climate sensitivity analysis ( $\pm 10 \%$ historic) using stochastic (100 replicates) driving variables.

version of the model versus -233.4 and -237.06 fasl and salinities of 56,335 and $61,598 \mathrm{mg} / \mathrm{L}$ for scenarios 2 and 3, respectively (Figure 5, Table 4). For both deterministic and stochastic versions of the model, the ANOVA (Tables 4 and 5) and Bonferroni multiple comparisons post hoc tests results revealed a statistically significant difference $(P<0.05)$ for the sea's elevations and salinities between the baseline climate scenario versus climate scenarios 2 and 3, as well as the elevations and salinities between climate scenarios 2 and 3 themselves.

\section{Conclusions}

The results of the logistic regression and curve fitting analyses provided valuable insight into the dynamics between single versus multiple Prcp events and the interaction between ETo and Prcp in the SS watershed, both of which are essential to the development of the aforementioned future climate scenario methodology. Results show that months with a larger percentage of Prcp events had a larger percentage of days with low ETo. Similar to the Sahara desert study by Scott et al. [35], the effect of a Prcp event had a negative effect on ETo in the semiarid environment around the SS but elucidated a more complex relationship. The results demonstrate that the longer the duration of the Prcp event, the larger the decrease in ETo volumes, in general, and for a longer period of time. Likewise, larger Prcp volume events suppress ETo volumes more so than smaller Prcp events. Based on the multinomial logistic regression models, the duration of the Prcp event is a slightly better predictor of ETo volumes than the Prcp volume associated with the Prcp event. Overall, ETo and Prcp exhibited a negative relationship.

The present study quantifies the relationships between ETo and Prcp in a semiarid region and provides a technique for maintaining these relationships in research involving stochastic climate simulation modeling. The overall low Pseudo $R^{2}$ values of the multinomial regression models lend support for using this strategy. The curve-fitting results for each monthly dataset resulted in similar distributions providing the "best" fit to the data; however, the distributions for the averaged monthly TIBC dataset often varied, more so for ETo than Prcp. Therefore, if more detailed weather patterns and accuracy in resulting fluctuations are important to the research question being addressed, then individual distributions should be incorporated for respective months when modeling future climate scenarios, such as in the SS watershed.

Concerning climate futures, a comparison can be made between the two strategies that were used in modeling the uncertainty in future climate projections: (1) the deterministic version of the driving variables and (2) the stochastic version of the driving variables. The difference between end simulation baseline mean elevations between the two strategies was less than 3 feet, that is, range of baseline minimum and maximum. The climate sensitivity analyses revealed that the cumulative effects and change of \pm 10 percent in SS inflows over the period of analysis can have significant effects $(P<0.05)$ on sea elevation and salinity, thereby demonstrating the importance of including climate uncertainty in the model.

According to climate model projections by Seager et al. [59], the Colorado River headwaters are expected to have an annual stream flow decline of 10 percent and as much as a 20 percent drop in spring runoff in California and Nevada, as warmer temperatures of $1-2^{\circ} \mathrm{C}$ also boost evaporation in 2021-2040. Given that the $\mathrm{S}^{4} \mathrm{M}$ has been constructed, tested, and validated, one can use it to test many different climate scenarios and the implications that climate change may hold for policy making in the region. One can use the climate modeling method constructed and tested herein to test many different climate scenarios and the implications that climate change may hold for policy making in the region, as well as applying the technique to other semiarid regions. In future research, alternative future scenarios can be defined and used 
TABLE 4: Salton Sea (SS) climate sensitivity analysis: one-way ANOVA descriptives.

\begin{tabular}{|c|c|c|c|c|c|c|c|c|}
\hline \multirow{2}{*}{ (I) trial } & \multirow{2}{*}{$N$} & \multirow[b]{2}{*}{ Mean } & \multirow{2}{*}{ Std. deviation } & \multirow{2}{*}{ Std. error } & \multicolumn{2}{|c|}{ 95\% Confidence interval for mean } & \multirow[b]{2}{*}{ Minimum } & \multirow[b]{2}{*}{ Maximum } \\
\hline & & & & & Lower bound & Upper bound & & \\
\hline \multicolumn{9}{|c|}{ SS elevation $^{\mathrm{a}}$} \\
\hline 1 & 100 & -235.38 & 0.00 & 0.00 & -235.38 & -235.38 & -235.39 & -235.37 \\
\hline 2 & 100 & -233.38 & 0.01 & 0.00 & -233.38 & -233.37 & -233.38 & -233.37 \\
\hline 3 & 100 & -237.09 & 0.01 & 0.00 & -237.09 & -237.08 & -237.09 & -237.08 \\
\hline Total & 300 & -235.28 & 1.52 & 0.09 & -235.45 & -235.11 & -237.09 & -233.37 \\
\hline \multicolumn{9}{|c|}{ SS salinity ${ }^{a}$} \\
\hline 1 & 100 & 59,292 & 5 & 1 & 59,291 & 59,293 & 59,277 & 59,306 \\
\hline 2 & 100 & 56,533 & 5 & 1 & 56,532 & 56,534 & 56,521 & 56,546 \\
\hline 3 & 100 & 61,903 & 6 & 1 & 61,902 & 61,905 & 61,891 & 61,916 \\
\hline Total & 300 & 59,243 & 2,196 & 127 & 58,993 & 59,492 & 56,521 & 61,916 \\
\hline \multicolumn{9}{|c|}{ SS elevation ${ }^{\mathrm{b}}$} \\
\hline 1 & 100 & -235.36 & 1.00 & 0.10 & -235.55 & -235.16 & -238.18 & -233.23 \\
\hline 2 & 100 & -233.40 & 1.77 & 0.18 & -233.75 & -233.05 & -236.52 & -227.72 \\
\hline 3 & 100 & -237.06 & 0.90 & 0.09 & -237.24 & -236.88 & -238.98 & -234.35 \\
\hline Total & 300 & -235.27 & 1.97 & 0.11 & -235.49 & -235.05 & -238.98 & -227.72 \\
\hline \multicolumn{9}{|c|}{ SS salinity ${ }^{b}$} \\
\hline 1 & 100 & 59,025 & 1,450 & 145 & 58,737 & 59,312 & 56,073 & 63,380 \\
\hline 2 & 100 & 56,335 & 2,245 & 225 & 55,890 & 56,781 & 49,703 & 60,731 \\
\hline 3 & 100 & 61,598 & 1,415 & 141 & 61,317 & 61,879 & 57,634 & 64,712 \\
\hline Total & 300 & 58,986 & 2,768 & 160 & 58,671 & 59,300 & 49,703 & 64,712 \\
\hline
\end{tabular}

Climate sensitivity analysis: ${ }^{\mathrm{a}}$ deterministic model results; ${ }^{\mathrm{b}}$ stochastic model results.

(I) trial: $1=$ baseline, $2=+10 \%, 3=-10 \%$.

Elevation units $=$ feet above sea level.

Salinity $=\mathrm{mg} / \mathrm{L}$.

TABLE 5: Salton Sea (SS) climate sensitivity analysis: one-way ANOVA results.

\begin{tabular}{|c|c|c|c|c|c|}
\hline & Sum of squares & $\mathrm{df}$ & Mean square & $F$ & Sig. \\
\hline \multicolumn{6}{|l|}{ SS elevation $^{\mathrm{a}}$} \\
\hline Between groups & 689.7 & 2 & 344.9 & 15200536.0 & 0.000 \\
\hline Within groups & 0.0 & 297 & 0.0 & & \\
\hline Total & 689.7 & 299 & & & \\
\hline \multicolumn{6}{|l|}{ SS salinity ${ }^{\mathrm{a}}$} \\
\hline Between groups & 1442505659.6 & 2 & 721252829.8 & 24552559.5 & 0.000 \\
\hline Within groups & 8724.6 & 297 & 29.4 & & \\
\hline Total & 1442514384.2 & 299 & & & \\
\hline \multicolumn{6}{|l|}{ SS elevation ${ }^{\mathrm{b}}$} \\
\hline Between groups & 670.9 & 2 & 335.4 & 203.6 & 0.000 \\
\hline Within groups & 489.2 & 297 & 1.6 & & \\
\hline Total & 1160.1 & 299 & & & \\
\hline \multicolumn{6}{|l|}{ SS salinity ${ }^{\mathrm{b}}$} \\
\hline Between groups & 1385130746.6 & 2 & 692565373.3 & 227.2 & 0.000 \\
\hline Within groups & 905456580.5 & 297 & 3048675.4 & & \\
\hline Total & 2290587327.1 & 299 & & & \\
\hline
\end{tabular}

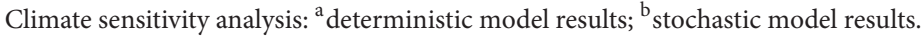

to explore the hydrologic and environmental implications of variations in, among other things, climate change and waterrelated policy decisions.

\section{Conflict of Interests}

The authors declare that there is not a conflict of interests regarding the present research.

\section{Acknowledgments}

The authors would like to thank Craig Forster, Edith González Afanador, and Ann L. Kenimer for their assistance. T. W. Clumpkin provided a thorough review. Financial support for this study was provided by the Southwest Consortium for Environmental Research and Policy (SCERP) through a cooperative agreement with the US Environmental Protection Agency. 


\section{References}

[1] G. M. MacDonald, "Water, climate change, and sustainability in the Southwest," Proceedings of the National Academy of Sciences of the United States of America, vol. 107, no. 50, pp. 21256-21262, 2010.

[2] J. A. Vano, T. Das, and D. P. Lettenmaier, "Hydrologic sensitivities of Colorado River runoff to changes in precipitation and temperature," Journal of Hydrometeorology, vol. 13, pp. 932-949, 2012.

[3] D. R. Cayan, T. Das, D. W. Pierce, T. P. Barnett, M. Tyree, and A. Gershunova, "Future dryness in the Southwest US and the hydrology of the early 21st century drought," Proceedings of the National Academy of Sciences of the United States of America, vol. 107, no. 50, pp. 21271-21276, 2010.

[4] D. S. Wilks, "Multisite generalization of a daily stochastic precipitation generation model," Journal of Hydrology, vol. 210, no. 1-4, pp. 178-191, 1998.

[5] S. Fatichi, V. Y. Ivanov, and E. Caporali, "Simulation of future climate scenarios with a weather generator," Advances in Water Resources, vol. 34, no. 4, pp. 448-467, 2011.

[6] C. W. Richardson and D. A. Wright, "WGEN: a model for generating daily weather variables," USDA Agricultural Research Service ARS-8, 1984.

[7] G. A. Baigorria and J. W. Jones, "GiST: a stochastic model for generating spatially and temporally correlated daily rainfall data," Journal of Climate, vol. 23, no. 22, pp. 5990-6008, 2010.

[8] R. Leander and T. A. Buishand, "A daily weather generator based on a two-stage resampling algorithm," Journal of Hydrology, vol. 374, no. 3-4, pp. 185-195, 2009.

[9] A. Mezghani and B. Hingray, "A combined downscalingdisaggregation weather generator for stochastic generation of multisite hourly weather variables over complex terrain: development and multi-scale validation for the Upper Rhone River basin," Journal of Hydrology, vol. 377, no. 3-4, pp. 245-260, 2009.

[10] B. Rajagopalan, U. Lall, D. G. Tarboton, and D. S. Bowles, "Multivariate non-parametric resampling scheme for generation of daily weather variables," Stochastic Hydrology and Hydraulics, vol. 11, pp. 65-93, 1997.

[11] D. S. Wilks, "Simultaneous stochastic simulation of daily precipitation, temperature and solar radiation at multiple sites in complex terrain," Agricultural and Forest Meteorology, vol. 96, no. 1-3, pp. 85-101, 1999.

[12] E. H. Chin, "Modeling daily precipitation occurrence process with Markov Chain," Water Resources Research, vol. 13, no. 6, pp. 949-956, 1977.

[13] T. Chapman, "Stochastic modelling of daily rainfall: the impact of adjoining wet days on the distribution of rainfall amounts," Environmental Modelling and Software, vol. 13, no. 3-4, pp. 317324, 1998

[14] R. Srikanthan and T. A. McMahon, "Stochastic generation of annual, monthly and daily climate data: a review," Hydrology and Earth System Sciences, vol. 5, no. 4, pp. 653-670, 2001.

[15] T. I. Harrold, A. Sharma, and S. J. Sheather, "A nonparametric model for stochastic generation of daily rainfall amounts," Water Resources Research, vol. 39, no. 12, 2003.

[16] D. S. Wilks and R. L. Wilby, "The weather generation game: a review of stochastic weather models," Progress in Physical Geography, vol. 23, no. 3, pp. 329-357, 1999.
[17] T. A. Buishand, "Some remarks on the use of daily rainfall models," Journal of Hydrology, vol. 36, no. 3-4, pp. 295-308, 1978.

[18] R. Srikanthan and G. G. S. Pegram, "A nested multisite daily rainfall stochastic generation model," Journal of Hydrology, vol. 371, no. 1-4, pp. 142-153, 2009.

[19] W. P. Miller, T. C. Piechota, S. Gangopadhyay, and T. Pruitt, "Development of streamflow projections under changing climate conditions over Colorado River basin headwaters," Hydrology and Earth System Sciences, vol. 15, no. 7, pp. 21452164, 2011.

[20] T. A. McMahon, M. C. Peel, L. Lowe, R. Srikanthan, and T. R. McVicar, "Estimating actual, potential, reference crop and pan evaporation using standard meteorological data: a pragmatic synthesis," Hydrology and Earth System Sciences, vol. 17, pp. 13311363, 2013.

[21] J. J. Beersma and T. A. Buishand, "Multi-site simulation of daily precipitation and temperature conditional on the atmospheric circulation," Climate Research, vol. 25, no. 2, pp. 121-133, 2003.

[22] R. L. Snyder, S. Geng, M. Orang, and S. Sarreshteh, "Calculation and simulation of evapotranspiration of applied water," Journal of Integrative Agriculture, vol. 11, no. 3, pp. 489-501, 2012.

[23] N. S. Christensen and D. P. Lettenmaier, "A multimodel ensemble approach to assessment of climate change impacts on the hydrology and water resources of the Colorado River Basin," Hydrology and Earth System Sciences, vol. 11, no. 4, pp. 1417-1434, 2007.

[24] G. A. Baigorria, "Stochastic models to generate geospatial-, temporal-, and cross-correlated daily maximum and minimum temperatures," Advances in Meteorology, vol. 2014, Article ID 365362, 14 pages, 2014.

[25] R. G. Allen, I. A. Walter, R. L. Elliott et al., The ASCE Standardized Reference Evapotranspiration Equation, American Society of Civil Engineers, Reston, Va, USA, 2005.

[26] M. J. Cohen, E. P. Glenn, and J. I. Morrison, "Haven or hazard: the ecology and future of the Salton Sea," A Report of the Pacific Institute, Executive Overview, 1999, http://www.sci.sdsu.edu/ salton/EcoSaltonSeaPacInstExeSum.html.

[27] M. J. Cohen and K. H. Hyun, HAZARD-The Future of the Salton Sea With No Restoration Project, Pacific Institute for Studies in Development, Environment, and Security, Oakland, Calif, USA, 2006.

[28] M. E. Kjelland, The future of the salton sea under proposed lower colorado river basin water management scenarios [Ph.D. dissertation], Department of Wildlife \& Fisheries Sciences, Texas A\&M University, 2008.

[29] Isee Sytems, "STELLA 8.0 software," Lebanon, New Hampshire, USA, 2006.

[30] S. Naoum and I. K. Tsanis, "Hydroinformatics in evapotranspiration estimation," Environmental Modelling and Software, vol. 18, no. 3, pp. 261-271, 2003.

[31] L. Castañeda and P. Rao, "Comparison of methods for estimating reference evapotranspiration in Southern California," Journal of Environmental Hydrology, vol. 13, no. 14, pp. 1-10, 2005.

[32] V. P. Singh, Hydrologic System-Rainfall-Runoff Modeling, Prentice-Hall, Englewood Cliffs, NJ, USA, 1988.

[33] R. G. Allen, L. S. Pereira, D. Raes, and M. Smith, "Crop evapotranspiration-guidelines for computing crop water requirements," FAO Irrigation and Drainage No. 56, Food and Agriculture Organization of the United Nations, Rome, Italy, 1998. 
[34] A. Munévar, Hydrology Development and Future Hydrologic Scenarios for the Salton Sea Ecosystem Restoration Program PEIR: Inflows/Modeling Working Group Preliminary Draft, 2006.

[35] R. Scott, D. Entekhabi, R. Koster, and M. Suarez, "Timescales of land surface evapotranspiration response," Journal of Climate, vol. 10, no. 4, pp. 559-566, 1997.

[36] C. B. Cook, G. T. Orlob, and D. W. Huston, "Simulation of winddriven circulation in the Salton Sea: implications for indigenous ecosystems," Hydrobiologia, vol. 473, pp. 59-75, 2002.

[37] W. W. Walker, "Simplified procedures for eutrophication assessment and prediction: user manual," Instruction Report W-962, U.S. Army Corps of Engineers, Water Operations Technical Support Program, U.S. Army Engineer Waterways Experiment Station, Vicksburg, Miss, USA, 1996.

[38] M. Anderson, "Appendix I-predicted water quality in the southern impoundments," in Evaluation of a Proposal for Conversion of the Salton Sea Ecosystem, U.S.D.I. Salton Sea Science Office, Ed., pp. 1-38, The Pacific Institute for Studies in Development, Environment and Security, Oakland, Calif, USA, 2002.

[39] Tetra Tech, Salton Sea Restoration Project Environmental Impact Statement/Environmental Impact Report (Draft), Prepared for the Salton Sea Authority and U.S. Department of Interior Bureau of Reclamation, Boulder City, Nev, USA, 2000.

[40] E. G. Chung, S. G. Schladow, J. Perez-Losada, and D. M. Robertson, "A linked hydrodynamic and water quality model for the Salton Sea," Hydrobiologia, vol. 604, no. 1, pp. 57-75, 2008.

[41] California Irrigation Management Information System (CIMIS), Spatial CIMIS, Department of Water Resources, Office of Water Use Efficiency, Sacramento, California, USA, 2013, http://wwwcimis.water.ca.gov/cimis/cimiSatStationLocation.jsp.

[42] National Climatic Data Center (NCDC), Climate Data Online: Text \& Map Search, National Oceanic and Atmospheric Administration (NOAA), Asheville, NC, USA, 2013, http://www.ncdc.noaa.gov/cdo-web/\#t=firstTabLink.

[43] A. A. Voinov, H. C. Fitz, and R. Costanza, "Surface water flow in landscape models: 1. Everglades case study," Ecological Modelling, vol. 108, no. 1-3, pp. 131-144, 1998.

[44] S. J. Bhuyan, K. R. Mankin, and J. K. Koelliker, "Watershedscale AMC selection for hydrologic modeling," Transactions of the American Society of Agricultural Engineers, vol. 46, no. 2, pp. 303-310, 2003.

[45] Salton Sea Ecosystem Restoration Program, Hydrology Development and Future Hydrologic Scenarios for the Salton Sea Ecosystem Restoration Program PEIR, Inflows/Modeling Working Group Preliminary Draft, Department of Water Resources, Colorado River and Salton Sea Office, Sacramento, Calif, USA, 2006.

[46] "MathWave Technologies (EasyFit Version 1.3)," Topol-3, 30/2/27, Dnepropetrovsk, Ukraine, 2006, http://www.mathwave.com/.

[47] A. Agresti, An Introduction to Categorical Data Analysis, John Wiley \& Sons, New York, NY, USA, 2nd edition, 1996.

[48] D. W. Hosmer and S. Lemeshow, Applied Logistic Regression, John Wiley \& Sons, New York, NY, USA, 2nd edition, 2000.

[49] StataCorp, "Stata Statistical Software: Release 9.0," College Station, Tex, USA, 2005.

[50] Environmental Systems Research Institute (ESRI), ArcGIS Desktop: Release 9 [Software], Environmental Systems Research Institute, Redlands, Calif, USA, 2004.
[51] Salton Sea Digital Atlas, Redlands Institute, University of Redlands, Redlands, Calif, USA, 2004, http://www.spatial.redlands .edu/salton/.

[52] S. T. Y. Tong and W. Chen, "Modeling the relationship between land use and surface water quality," Journal of Environmental Management, vol. 66, no. 4, pp. 377-393, 2002.

[53] SPSS, SPSS Base 12.0.1 for Windows User's Guide, SPSS, Chicago, Ill, USA, 2003.

[54] Imperial Irrigation District Water Department (IIDWD) and CH2MHill, Imperial Irrigation Decision Support System Summary Report (Draft), Redding, Calif, USA, 2001.

[55] Department of Water Resources, Colorado River and Salton Sea Office, Hydrology Development and Future Hydrologic Scenarios for the Salton Sea Ecosystem Restoration Program PEIR, Inflows/Modeling Working Group Preliminary Draft, Salton Sea Ecosystem Restoration Program, Sacramento, Calif, USA, 2006.

[56] Colorado River Board of California, Report to the California Legislature on the Current Condition of the Salton Sea and the Potential Impacts of Water Transfers, 1992, http://www.sci.sdsu .edu/salton/PotentialImpactsSaltonSea.html.

[57] M. J. Cohen, "Water brief 2-past and future of the Salton Sea," in The World's Water 2008-2009: The Biennial Report on Freshwater Resources, P. H. Gleick, H. Cooley, and M. Morikawa, Eds., vol. 6 of World's Water, pp. 127-138, Island Press, 2009.

[58] U.S. Army Corps of Engineers (USACE) and California Natural Resources Agency (CNRA), "Salton sea species conservation habitat project," Draft Environmental Impact Statement/Environmental Impact Report No. SPL-2010-00142-LLC, State Clearinghouse No. 2010061062, Prepared for the California Natural Resources Agency by the Department of Water Resources and Department of Fish and Game. U.S. Army Corps of Engineers Application, 2011.

[59] R. Seager, M. Ting, C. Li et al., "Projections of declining surfacewater availability for the southwestern United States," Nature Climate Change, vol. 3, pp. 482-486, 2012. 

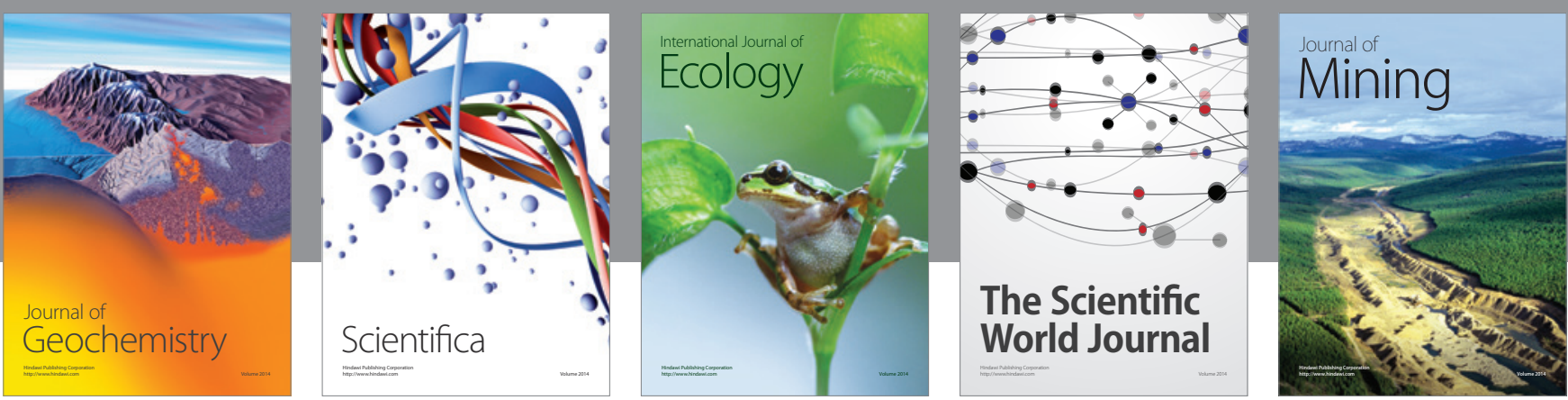

The Scientific World Journal
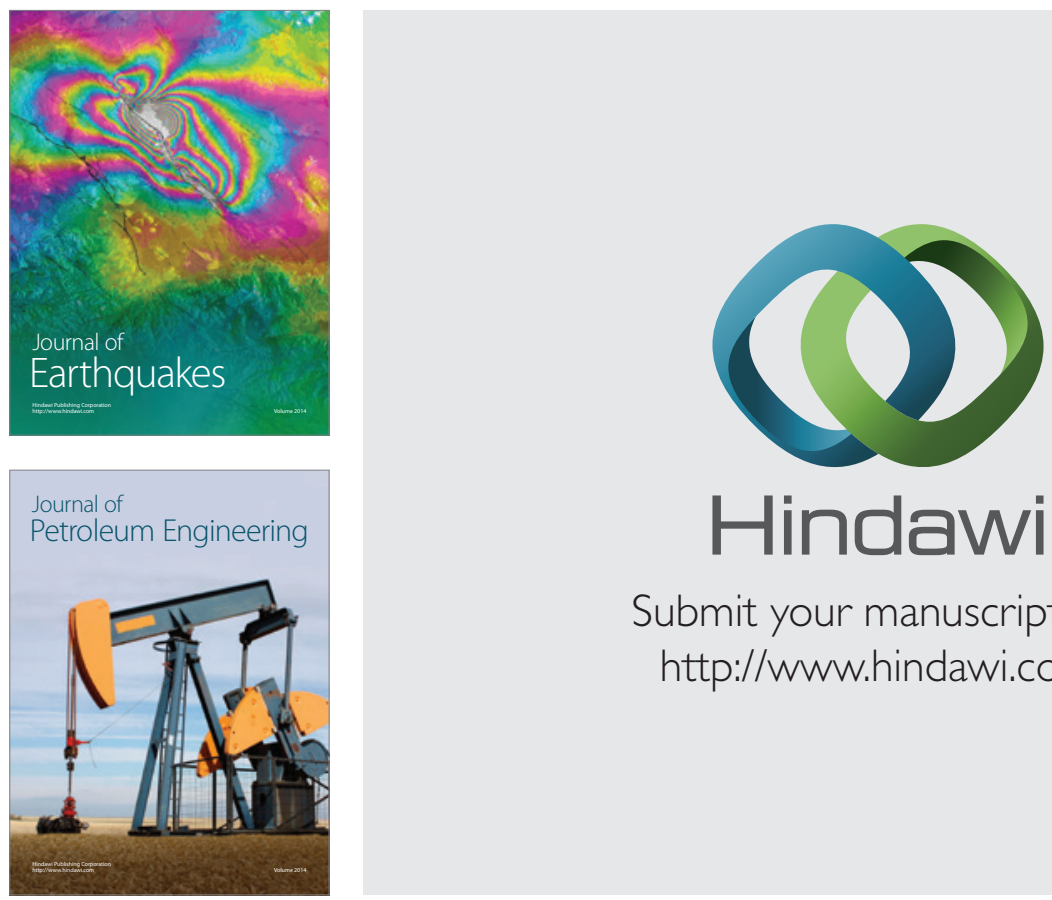

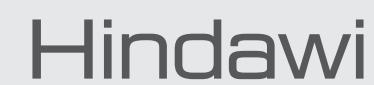

Submit your manuscripts at

http://www.hindawi.com
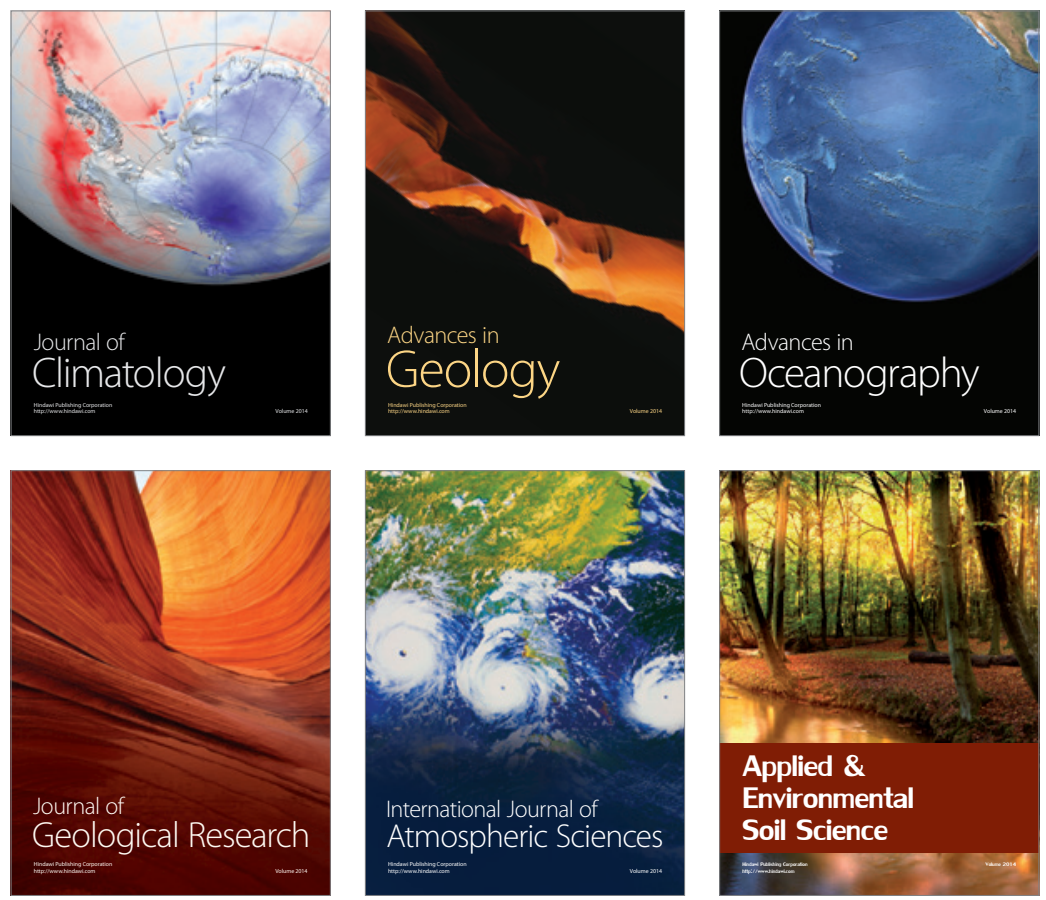
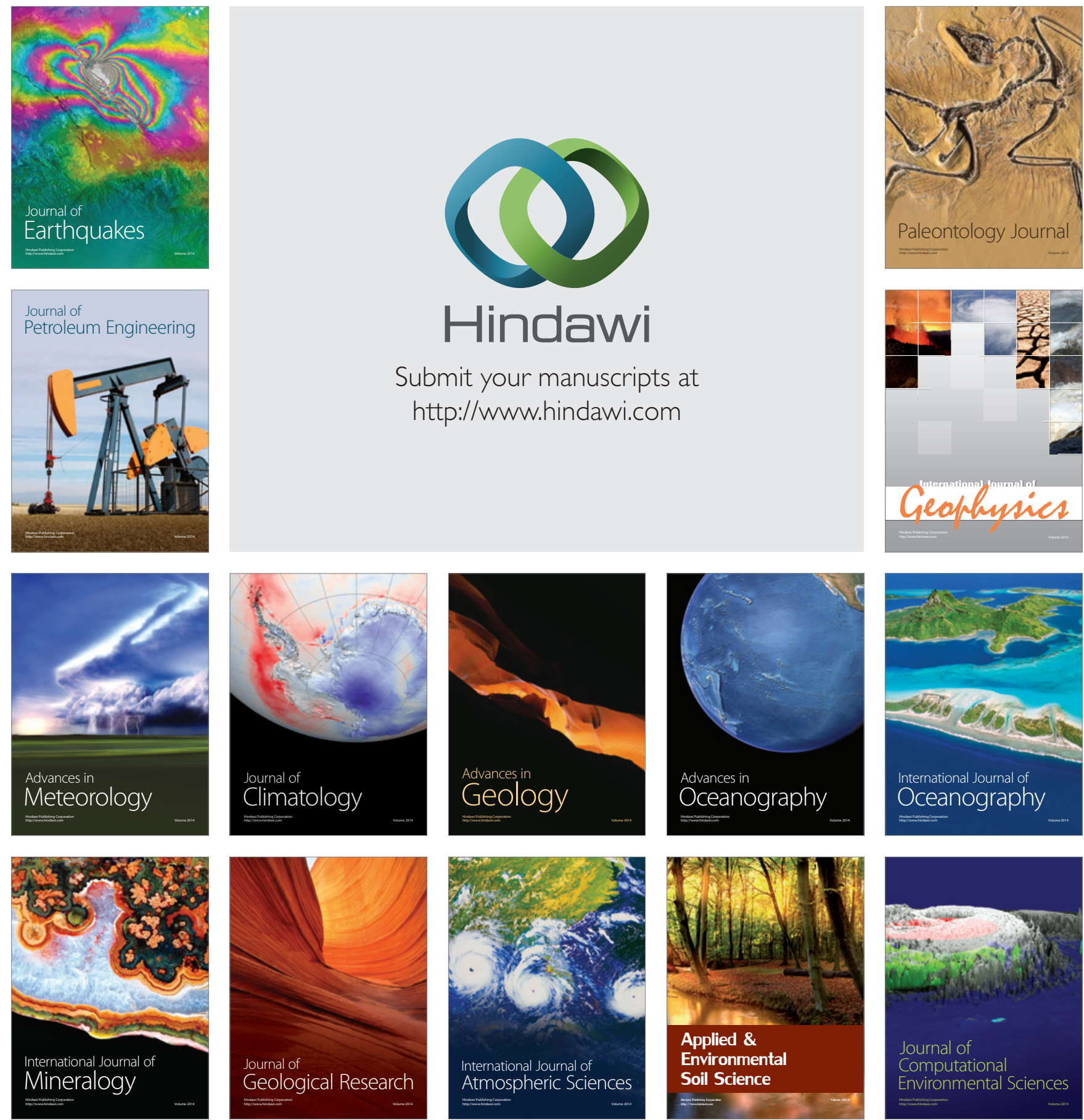